\title{
Acral Lentiginous Melanoma, Rare Form of Marjolin's Ulcer: A Case and Literature Review
}

\author{
N. Siska Ananda ${ }^{1}$, R. R. Natasha Roosseno ${ }^{2}$ \\ ${ }^{1,2}$ Departement of Plastic Surgery, Mangusada Hospital, Badung, Bali
}

\begin{abstract}
Marjolin's ulcer is a cutaneous malignancy that previously traumatized and chronically inflammed. The incidence of Marjolin's ulcer in acral lentiginous melanoma form is extremely low. We report the first Marjolin's ulcer in our hospital, which developed from chronic wound 20 years after traumatic injury. Wide local excision was performed and it was diagnosed histopathologically as acral lentiginous melanoma.
\end{abstract}

Keywords: marjolin's ulcer, acral lentiginous melanoma.

\section{Introduction}

Marjolin's ulcer is a rare case, which the chronic wound changes into malignant form. Marjolin's ulcer most commonly develops from burn injury [1],[2]. In addition, it can also develop from chronic osteomyelitis, traumatic injury, diabetic ulcers, pressure ulcer, and vaccination site [1]-[7]. The most common form of marjolin's ulcer is squamous cell carcinoma (SCC), a small proportion of cases is basal cell carcinoma (BCC) and malignant melanoma (MM) [1],[2],[4]-[11]. There are four types of MM in the skin: superficial spreading melanoma, lentigo malignant melanoma, nodular melanoma and acral lentiginous melanoma. Acral lentiginous melanoma is the most rare form of malignant melanoma, an incidence rate is only $1 \%$ of all malignant melanoma [12]. In this report, the first marjolin's ulcer case at our hospital will be presented, which is also a very rare form of marjolin's ulcer.

\section{Case Presentation}

A 53-year-old man came to our hospital's outpatient department complaining a sore lump on his right plantar heel. The lump appeared first 3 months ago. Before the lump emerged, the patient claimed that his heel was punctured by plant spines about 20 years ago. One year after the incident, there was a blackish color on that scar that continued to widen. Because it was not painful, he ignored it until about 20 years later, but small bumps grew on it. Three months passed, the size of the lump was longer and greater, because it felt pain finally he checked into the hospital. Previously he had never checked it anywhere. The patient also said he had no history of any illness, nor did his family. The daily work of the patient was gardening using boots. Patient has no smoking history.

Initial examination showed the presence of $2 \mathrm{~cm} \times 2 \mathrm{~cm}$ solid mass, non-mobile, firm, flat, with $3 \mathrm{~cm} \times 4 \mathrm{~cm}$ borderless hyperpigmented base skin (Figure 1). Patient was planned for wide excision and histological examination.

The wide local excision was performed about $2 \mathrm{~cm}$ beyond the border of hyperpigmentation area. Temporary injuries prevalence of SCC is balanced between men and women, but were treated with honey while awaiting the results of histopathology examination. While waiting for the results of histopathology examination for about 2 weeks, the excision wound responded well with the treatment of honey.

The histopathology examination results from tumor specimens showed that the malignant melanoblast cells located in the dermis was invasive to reticular dermis. The tumor cells were partly epitheloid and partly spindle. The surface of the tumor looked ulcerative. Tumor thickness was about $\pm 10 \mathrm{~mm}$. At the medial and posterior edges, it was composed of epidemic keratin layer without tumor cell extension. On the lateral edges, there were some focal nests of atypical melanocyte cells in the basal epidermis. In the dermis, it did not appear expansion of tumor cells. From these examinations we could conclude the morphological picture of a biopsy specimen was suitable for acral lentiginous melanoma with vertical growth phase Clark level IV. The edges of the specimen were free of malignant cells. Treatment with honey was continued until the wound surgery closes perfectly for 2 months (Figure 2).

\section{Discussion}

Marjolin's ulcer is a rare condition where the previously injured and inflamed skin chronically transformed into a malignancy. In 1828, a French surgeon named Jean Nicholas Marjolin defined this condition as a malignant changes of scar tissue [1],[2].

Burns are the most common injuries that develop into Marjolin's ulcer. In addition Marjolin's ulcer can also originate from chronic osteomyelitis, discoid lupus erythematosus lesions, amputation stumps, chronic fistulas, vaccination site, frostbite, diabetic ulcers, pressure ulcers, chronic venous ulcers, and other chronic wounds [1]-[7] Another study in 1996 reported a case of Marjolin's ulcer that developed from chronic wounds 42 years after stumbling stone [13]

Between 1923 and 2004, 1078 cases of marjolin's ulcer were recorded in the Kowal-Vern and Criswell studies in 2005. $71 \%$ were diagnosed as SCC, $12 \% \mathrm{BCC}$ and $6 \% \mathrm{MM}$. The $\mathrm{BCC}$ generally occurs in men, whereas melanoma is mostly 


\section{International Journal of Science and Research (IJSR) \\ ISSN (Online): 2319-7064}

Index Copernicus Value (2015): 78.96 | Impact Factor (2015): 6.391

afflicted by women. Most of the cases of marjolin's ulcer originated from minor burns with the shortest latent period is BCC [14].

The main risk factors of Marjolin's ulcer are wounds with prolonged healing time [1]. Male as well as immunocompromised conditions are more at risk for Marjolin's ulcer [5],[7]-[9],[15]-[19]. Marjolin's ulcer is more commonly found in the lower extremities especially on the soles of the feet and scalp [1],[2],[5],[7],[8],[15],[20]. The average length of a wound to develop into Marjolin's ulcer is $32.4 \pm 18.5$ years [8]. Although there is some research that says marjolin's ulcer can develop less than 1 year after injury [5],[8].

There are some pathophysiology theories of Marjolin's ulcer's, among them said that it is caused by mutagenic accumulation with mitotic activities aimed for regeneration, production of carcinogenic toxins by scar tissue, inadequate immunological reactions in scarring areas, chronic irritation, recurrent trauma and possible DNA damage in the area [1],[6]-[8],[16],[21].

The diagnosis of Marjolin's ulcer can be established based on anamnesis, physical examination and supportive examination. From anamnesis patients usually get complained of wounds that never healed for more than 3 months, the size of the wound enlarged, as well as other risk factors such as immunocompromised conditions. From the physical examination, the classic triage is obtained, which is formation of nodules, induration and ulceration at the scar location. In addition, also found wounds with edging edges, excess granulation tissue, unpleasant odor, enlargement, bleeding and pain [16],[20],[21],[22].

In this case a 53-year-old man had an enlarged and painful mass on his right plantar heel after impaled by thorn about 20 years ago. Chronic inflammation was suspected as a result of daily activities when patients walking every day for almost 10 hours per day as a gardener. At the bottom of the mass, we found hyperpigmented skin with the ulcerative edge surround the mass.

Until now surgery is the generally recommended modality for skin malignancy treatment, which is done by local excision involving $2 \mathrm{~cm}$ to $4 \mathrm{~cm}$ of healthy tissue around it. However, this method does not guarantee a $0 \%$ recurrence rate. Oruc's study conducted in 2017 showed an average recurrence occurred 15 months after surgery on skin malignancy, especially Marjolin's ulcer degrees II and III [1],[2],[4],[6],[7],[23],[24].

Biopsy is a gold standard examination to determine the presence of malignant cells. The larger the size of the lesion, the greater the number of biopsied regions [1],[2],[4][11],[15]-[17]. In this case, the wide local excision and histopathology examination had been done and the result was acral lentiginous melanoma with vertical growth phase of Clark level IV.

Acral lentiginous melanoma is an aggressive and malignant form of MM. Of the overall incidence of MM, acral lentiginous melanoma occurs only by $1 \%$. Most of the acral lentiginous melanoma incidents occur at over 60 years of age, in Asian, Indian, Middle Eastern and African races. Approximately $65 \%$ of cases of acral lentiginous melanoma occur on the sole of the foot. Clinically, acral lentiginous melanoma can be seen in ulcerative forms, verukoid lesions, onychomycosis, tinea pedis, subungual hematoma, infection and vascular lesions, and other pathological forms. The symptoms mostly complained by patients were the enlargement of lesion size (38\%) and bleeding (19\%). As other melanoma cases, the prognosis of acral lentiginous melanoma is determined by Breslow thickness [12]. Based on "Melanoma Staging and Classification" by the American Joint Committee on Cancer in 2009, the survival rate in this case reached 5 years (53\%) to 10 years (39\%) ) [25].

Radiological examination can be done to determine the existence of bone involvement, but in this case radiology examination was not done because the patient refused. CT scans can be used to look at bone conditions, but MRI examinations can be performed to evaluate bone and soft tissue better. The margin of bone involvement can be displayed well through MRI so that it can assist the operation process [1],[7].

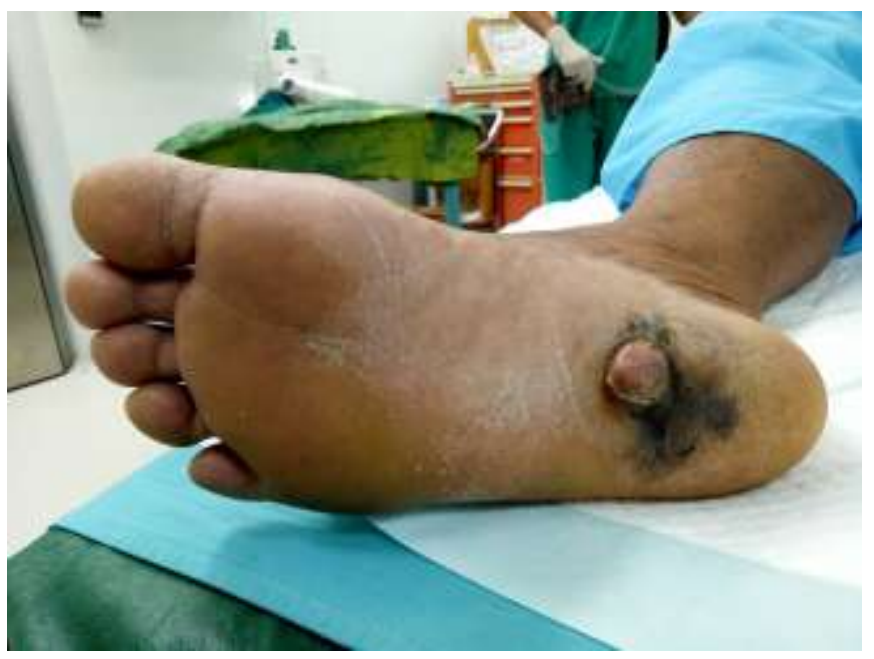

Figure 1: Initial clinical appearance

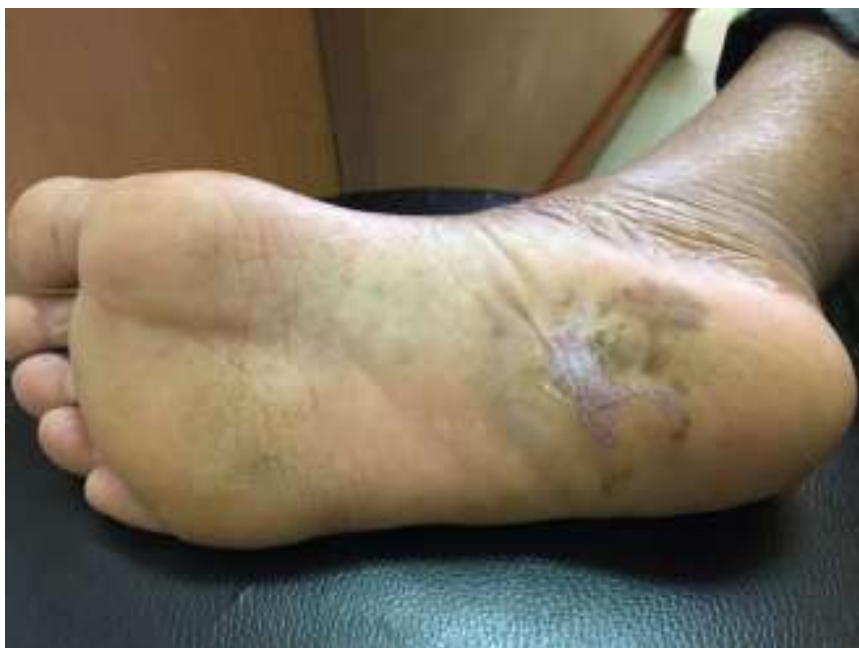

Figure 2: 8 weeks post-operative

\section{Volume 6 Issue 9, September 2017 \\ www.ijsr.net}

Licensed Under Creative Commons Attribution CC BY 


\section{International Journal of Science and Research (IJSR) \\ ISSN (Online): 2319-7064}

Index Copernicus Value (2015): 78.96 | Impact Factor (2015): 6.391

\section{Conclusion}

Further follow-up is still needed in this case to ensure either the presence or absence of recurrence and metastasis. Any injury that has chronic inflammation should receive attention to detect early onset of malignancy.

\section{References}

[1] Oruc M, Kankaya Y, Sungur N, Ozer K, Isik VM, Ulusoy MG, et al. Clinicopathological evaluation of Marjolin ulcers over two decades. Kaohsiung Journal of Medical Sciences. 2017;20:1-7

[2] Bernhard K, Morgan K, Kruse D, Stone PA. Rare Presentation of Marjolin's Ulcer Secondary to a PostTraumatic Injury. The Journal of Foot \& Ankle Surgery. 2016;30:1-5

[3] Pandey M, Kumar P, Khanna AK. Marjolin's ulcer associated with chronic osteomyelitis. J Wound Care. 2009;18(12):504-6.

[4] Yesilada AK, Sevim KZ, Sucu DO, Akcal A, Karsidag S, Kilinc L, et al. Marjolin's Ulcer: Clinical Experience with 34 Patients over 15 Years. J Cut Med Surg. 2013;17(6):404-9.

[5] Fazeli SM, Lebaschi AH, Hajirostam M, Keramati MR. Marjolin's ulcer: clinical and pathologic features of 83 cases and review of literature. Med J Islam Repub Iran. 2013;27:215-24.

[6] Khan K, Giannone AL, Mehrabi E, Khan A, Giannone RE. Marjolin's Ulcer Complicating a Pressure Sore: The Clock is Ticking. Am J Case Rep. 2016;17:111-14.

[7] Opara KO, Otene IC. Marjolin's Ulcers: A Review. Nigerian Health J. 2011;11(4):107-111.

[8] Ehsani AH, Noormohammadpour P, Nasiri N, Faraz PT, Goodarzi A. Demographic and histopathologic characteristics of Marjolin's ulcer in Razi Hospital, Tehran, Iran: A 5-year survey. Iran J Dermatol. 2016;19(2):45-9.

[9] Chalya PL, Mabula JB, Rambau P, Mchembe MD, Kahima KJ, Chandika AB, et al. Marjolin's ulcers at a university teaching hospital in Northwestern Tanzania: a retrospective review of 56 cases. World J Surg Oncol. 2012;10:38.

[10] Bozkurt M, Kapi E, Kuvat SV, Ozekinci S. Current Concepts in the Management of Marjolin's Ulcers: Outcomes From a Standardized Treatment Protocol in 16 Cases. J Burn Care Res. 2010;31:776-80.

[11] Sharma RK. Is Marjolin's ulcer always a squamous cell carcinoma? Shedding some light on the old problem. Plast Reconstr Surg. 2009;124:1005.

[12] Patel AK, Ferraro AJ. Acral lentiginous melanoma: A case and literature review. Foot and Ankle Online Journal. 2015;8(1):1-4.

[13] Hill BB, Sloan DA, Lee EY, McGrath PC, Kenady DE. Marjolin's ulcer of the foot caused by nonburn trauma. South Med J. 1996;89:707-710.

[14] Wallingford SC, Olsen CM, Plasmeijer E, Green AC. Skin Cancer Arising in Scars: A Systematic Review. 2011; Dermatol Surg. 2011;37:1239-1244.

[15] Onesti MG, Fino P. Fioramonti P, Amorosi V, Scuderi $\mathrm{N}$. Ten years of experience in chronic ulcers and malignant transformation. Int Wound J 2013;12(4):447-50.

[16] Asuquo M, Ugare G, Ebughe G, Jibril P. Marjolin's ulcer: the importance of surgical management of chronic cutaneous ulcers. Int J Dermatol. 2007;46:2932.

[17] Ko Y, Han YM, Hwang HS, Kang IW, Hwang DH, Lee ES, et al. Role of 18F-FDG PET/CT in the diagnosis of clinically suspected Marjolin's ulcer. Am J Roentgenol. 2012;199(6):1375-9.

[18] Tiftikcioglu YO, Ozek C, Bilkay U, Uckan A, Akin Y. Marjolin's Ulcers Arising on Extremities. Ann Plast Surg. 2010;64:318-20.

[19] Tahir C, Ibrahim BM, Terna-Yawe EH, Abbas AA, Umaru H, Mayun AA, et al. The increasing burden of Marjolin's ulcer in North Eastern Nigeria: A 10 year study and review of literature. Nigerian Journal of Plastic Surgery. 2012;8(1):14-8.

[20] Pekarek B, Buck S, Osher L. A Comprehensive Review on Marjolin's Ulcer: Diagnosis and Treatment. Journal of the American College of Certified Wound Specialists. 2011;3:60-4.

[21] Fairbairn NH, Hamilton SA. Management of Marjolin's ulcer in a chronic pressure sore secondary to paraplegia: a radical surgical solution. Int Wound J. 2011;8(5):533-36.

[22] Saaiq M, Ashraf B. Marjolin's ulcers in the postburned lesions and scars. World J Clin Cases. 2014;2(10):507-14.

[23] Sharma A, Schwartz RA, Swan KG. Marjolin's warty ulcer. J Surg Oncol. 2011;103:193-195.

[24] Iqbal FM, Sinha Y, Jaffe W. Marjolin's ulcer: a rare entity with a call for early diagnosis. BMJ Case Rep. 2015;10:1-5

[25] Balch CM, Gershenwald JE, Soong S, Thompson JF, Atkins MB, Byrd DR, et al. Final Version of 2009 AJCC Melanoma Staging and Classification. J Clin Oncol. 2009;27(36):6199-6206. 